\title{
Vasorelaxant effects of Angelica decursiva root on isolated rat aortic rings
}

\author{
Bumjung Kim ${ }^{1+}$, Youngki Kwon ${ }^{2+}$, Somin Lee ${ }^{2}$, Kyungjin Lee ${ }^{1}$, Inhye Ham and Ho-Young Choi ${ }^{1 *}$
}

\begin{abstract}
Background: Hypertension is one of the most important risk factors for cardiovascular disease (CVD) and a worldwide problem. Despite increases in the development of synthetic drugs for hypertension treatment, the rate of untreated and uncontrolled hypertension remains high. These drugs are effective, but can also cause side effects. Approximately $80 \%$ of the world population uses herbal medicines because of their low toxicity and better acceptability by the human body. Therefore, we attempted to identify natural medications for treating hypertension. The $70 \%$ ethanol extract of Angelica decursiva root (ADE) shows strong vasorelaxant potential, but no studies have investigated the mechanisms underlying the vasorelaxation effect of $A$. decursiva.

Methods: Dried root of $A$. decursiva was identified by DNA sequencing and was extracted once with $1 \mathrm{~L} 70 \%$ ethanol $(\mathrm{EtOH})$ for $3 \mathrm{~h}$ in a reflux apparatus at $70{ }^{\circ} \mathrm{C}$. ADE was evaluated for its vasorelaxant effects in rat thoracic aortas. Various inhibitors of ADE-induced vasorelaxation were used.

Results: ADE showed vasorelaxant effects on the intact and denuded endothelium of aortic rings pre-contracted with phenylephrine and $\mathrm{KCl}$ in Krebs-Henseleit solution. Tetraethylammonium and 4-aminopyridine did not alter ADEinduced vasorelaxation. However, the vasorelaxant effect of ADE was partially inhibited by pre-treatment with glibenclamide an ATP-sensitive $\mathrm{K}^{+}$channel blocker. Furthermore, ADE concentration-dependently inhibited $\mathrm{Ca}^{2+}$ supplementation-induced vasoconstriction of aortic rings that had been pretreated with phenylephrine or $\mathrm{KCl}$ in $\mathrm{Ca}^{2}$ ${ }^{+}$-free Krebs-Henseleit solution.
\end{abstract}

Conclusions: These results suggest that ADE-induced vasorelaxation occurred in an endothelium-independent manner. The vasorelaxant effects of ADE were correlated with blockade of the $\mathrm{K}_{\mathrm{ATP}}$ channel and inhibition of $\mathrm{Ca}^{2+}$ influx via receptor-operative $\mathrm{Ca}^{2+}$ channels or voltage-dependent $\mathrm{Ca}^{2+}$ channels.

Keywords: Angelica decursiva, Vasorelaxation, Hypertension, Receptor-operated calcium channels, Voltagedependent calcium channels

\section{Background}

Hypertension is one of the most important risk factors for cardiovascular disease (CVD) and a worldwide problem. The number of people with hypertension increased from 600 million in 1980 to 1 billion in 2008. CVD is predicted to cause one-fourth of all global deaths in 2030. Despite increases in the development of synthetic drugs for hypertension treatment, the rate of untreated and uncontrolled hypertension remains high [1]. The

\footnotetext{
* Correspondence: hychoi@khu.ac.kr

${ }^{\dagger}$ Equal contributors

'Department of Herbology, College of Korean Medicine, Kyung Hee University, 26 Kyungheedae-ro, Dongdaemun-gu, Seoul 02447, Republic of Korea

Full list of author information is available at the end of the article
}

World Health Organization (WHO) reported that 38 million (or $68 \%$ ) of 56 million human deaths worldwide were due to noncommunicable diseases (NCDs) in 2012. The four main NCDs are cardiovascular diseases (17.5 million deaths, or $46 \%$ of all NCD deaths), cancers (8.2 million, or $22 \%)$, respiratory diseases (4.0 million, or $10.7 \%)$, and diabetes (1.5 million, or 4\%) [2]. Three important causes of death in Korea are cancer, cerebrovascular disease, and heart disease, causing approximately $48.3 \%$ of all deaths in Korea [3].

Hypertension is defined as blood pressure higher than $140 / 90 \mathrm{mmHg}(130 / 80 \mathrm{mmHg}$ for patients with diabetes and chronic kidney disease), whereas prehypertension is defined as a blood pressure in the range 
120-139/80-89 mmHg in the Seventh Report of the Joint National Committee on Prevention, Detection, Evaluation, and Treatment of High Blood Pressure [4]. Hypertension is asymptomatic until it progresses to a life-threatening condition. If blood pressure increases continuously, the blood vessels of the heart, brain, and kidney can be damaged, leading to increased chances of renal failure, heart failure, coronary artery disease, stroke, and dementia [5]. Furthermore, if the primary conditions are accompanied by complications such as heart disease or stroke, the fatality rate markedly increases [6].

Various drugs such as diuretics, $\alpha$-blockers, $\beta$ blockers, $\mathrm{Ca}^{2+}$ channel blockers, angiotensinconverting enzyme inhibitors, angiotensin II receptor antagonists, and vasodilators are used to treat hypertension [7]. These drugs are effective, but also cause side effects such as dry cough [8], hyponatremia [9], impotence [10], and diabetes [11] among others. Approximately $80 \%$ of the world population uses various herbal medicines because of their low toxicity and better acceptability by the human body [12]. Additionally, one study showed that many plants used in Mexican traditional medicine for treating cardiovascular disease exhibit vasoactive and antioxidant activities [13]. Therefore, we evaluated the use of natural medications for hypertension treatment.

Angelica decursiva Fr. et. Sav., (=Peucedanum decursivum Maximowicz) is a perennial herb belonging to the Umbelliferae family of plants and grows widely in East Asia. The root of $A$. decursiva has been used in Korean traditional medicine as an expectorant, antipyretic, and cough remedy [14]. There are few studies of $A$. decursiva, which has antiinflammatory effects [15], inhibits growth of human head and neck squamous cell carcinomas [16], and induces apoptosis of human oral cancer cells [17]. The components of essential oil from $A$. decursiva are: $\alpha$-pinene (44.98\%), $\beta$ barbatene (8.56\%), germacrene-d (5.33\%), limonene (4.21\%), and $\beta$-pinene (3.81\%) [18]. A. decursiva contains various types of coumarin derivatives such as nodakenin, nodakenetin, decursin, decursidin, umbelliferone, scopoletin, bergapten, and imperatorin [19-21].

The Umbelliferae (Apiaceae) family comprises over 300455 genera and 3000-3750 species [22]. Numerous plants in this family have been used for both medicinal and alimentary purposes. Particularly, various herbal medicines such as A. dahurica [23], Ostericum koreanum [24], Ligusticum jeholense [25], L. wallichii, and A. gigas [26] were shown to have vasorelaxant effects. Thus, the purpose of this study was to screen the vasorelaxant activities of Umbelliferae medicinal plants. The $70 \%$ ethanol extract of A. decursiva root showed strong vasorelaxant potential; however, no studies have investigated the mechanisms underlying these effects.

\section{Methods}

Plant material and extraction

A. decursiva root was collected in Yongin, Gyeonggi province, Republic of Korea, in July 2015. The plant was identified by Professor Kyungjin Lee of Kyung Hee University. A voucher specimen (VS15071501) of the plant was deposited in the herbarium of the College of Korean Medicine, Kyung Hee University, Seoul, Republic of Korea. Dried $A$. decursiva root (100.0 g) was extracted once with $1 \mathrm{~L} 70 \%$ ethanol (EtOH) for $3 \mathrm{~h}$ in a reflux apparatus at $70{ }^{\circ} \mathrm{C}$. After filtration, the extract was evaporated in a rotary vacuum evaporator (N-N series, EYELA, Japan) at $60{ }^{\circ} \mathrm{C}$ and lyophilized in a freeze-dryer (Operon $^{\mathrm{Tm}}$, Seoul, Korea) to obtain a brown powder $(12.3 \mathrm{~g})$ of crude extract. The $70 \% \mathrm{EtOH}$ extract of $A$. decursiva (ADE) powder was accurately weighed $(0.1 \mathrm{~g})$, suspended in $1 \mathrm{ml} \mathrm{DMSO}$, and placed into an ultrasonic device for $1 \mathrm{~min}$ for solubilization. The powder was completely dissolved, and the color was dark brown.

\section{Reagents and equipment}

NucleoSpin Plant II kit (MACHERRY-NAGEL, GmbH \& Co. KG, Germany). Blend Taq (pfu) (Toyobo, Japan). Midori green direct (Nippon genetics, Japan). NucleoSpin Gel and PCR Clean-up (MACHERRY-NAGEL, GmbH \& Co. KG, Germany). ITS1 (5' -TCC GTA GGT GAA CCT GCG G-3'), ITS4 (5'-TCC TCC GCT TAT TGA TAT GC-3'), ITS2F (5'-ATG CGA TAC TTG GTG TGA AT-3'), and ITS3R (5' - GAC GCT TCT CCA GAC TAC AAT-3') primer (Macrogen Inc. Korea). Modified Krebs-Henseleit (KH) buffer powder, Phenylephrine (PE), acetylcholine (Ach), potassium chloride $(\mathrm{KCl})$, tetraethylammonium (TEA), glibenclamide, 4-aminopyridine (4-AP), calcium chloride $\left(\mathrm{CaCl}_{2}\right)$, ethylene glycol-bis (2-aminoethylether)$N, N, N^{\prime}, N^{\prime}$-tetra acetic acid (EGTA), and dimethyl sulfoxide (DMSO) were purchased from Sigma Aldrich (St. Louis, USA). All other reagents were of analytical purity.

In the present study a rotary vacuum evaporator (EYELA co., Japan), Freeze-dryer (Operon ${ }^{\mathrm{Tm}}$, Seoul, Korea), TissueLyser2 (Qiazen GmbH, Germany), T100 Thermal cycler (BIORAD, USA), Gel Doc EZ imager (BIORAD, USA), Isometric force transducer (Grass instrument Co., USA), Powerlab data acquisition system (ADI instrument Co., Australia) were used.

\section{Sequencing of PCR-amplified DNA from A. decursiva}

The dried root of $A$. decursiva was prepared for DNA sequencing. After crashing the plant sample through TissueLyser2 (Qiazen GmbH, Germany), DNA was extracted by NucleoSpin Plant II kit. For the $25 \mu \mathrm{l}$ PCR reaction, as universal primers for PCR of the ITS region, forward primer 'ITS1' and reverse primer 'ITS4' were used. Especially, forward primer ITS2F and reverse primer ITS3R were used for ITS2 region, respectively. The 
PCR reaction mix contained $20 \mathrm{ng}$ template DNA $1 \mu \mathrm{l}$ and 10 pmole primer $1 \mu \mathrm{l}$ in $3 \mu \mathrm{l}$ of Blend Taq (pfu). PCR conditions were as follows: 35 cycles of predenaturation at $94{ }^{\circ} \mathrm{C}$ for $2 \mathrm{~min}$; denaturation at $94{ }^{\circ} \mathrm{C}$ for $30 \mathrm{~s}$; annealing at $55{ }^{\circ} \mathrm{C}$ for $40 \mathrm{~s}$ and extension at $72{ }^{\circ} \mathrm{C}$ for $1 \mathrm{~min}$; and final extension at $72{ }^{\circ} \mathrm{C}$ for $1 \mathrm{~min}$ per $1 \mathrm{~kb}$. After PCR products were mixed with the Midori green direct, they separated on agarose gel for $40 \mathrm{~min}$ and visualized under UV light by using GelDoc. The amplified DNA band was purified with NucleoSpin Gel and PCR Clean-up kit and DNA sequence was analyzed at Macrogen Inc. (Korea).

\section{Animals and preparation of rat aortic rings}

Forty four male Sprague-Dawley rats (240-260 g; Raonbio, Gyeonggi province, Korea) were maintained under standard laboratory conditions $\left(22 \pm 2{ }^{\circ} \mathrm{C}\right.$; lighting, 07:0019:00) and were given ad libitum access to food and water. All procedures followed according to the animal welfare guidelines and were approved [KHUASP(SE)-15-066] by the Kyung Hee University Institutional Animal Care and Use Committee. The protocol of isolation and preparation of rat thoracic aorta for this study has been described previously [25].

\section{Experimental protocols \\ Vasorelaxant effects of ADE on PE (or $K C I$ )-induced contraction}

The aortic rings with endothelium were pre-contracted with $\mathrm{PE}(1 \mu \mathrm{M})$ or $\mathrm{KCl}(60 \mathrm{mM})$ in standard $\mathrm{KH}$ buffer. After equilibration period, various cumulative doses of ADE $(25-800 \mu \mathrm{g} / \mathrm{ml})$ were investigated. The vasorelaxant effect of ADE was expressed as percentages of the relaxation in response to $\mathrm{PE}$ or $\mathrm{KCl}$.

\section{Vasorelaxant effects of ADE with and without endothelium}

We investigated the concentration-dependent vasorelaxant effect of $\mathrm{ADE}(25-800 \mu \mathrm{g} / \mathrm{ml})$ on aorta rings with and without endothelium by $\mathrm{PE}(1 \mu \mathrm{M})$ or $\mathrm{KCl}(60 \mathrm{mM})$ in standard $\mathrm{KH}$ buffer. The vasorelaxant effect of ADE was expressed as percentages of the relaxation in response to $\mathrm{PE}$ or $\mathrm{KCl}$.

\section{Vasorelaxant effects of ADE on aortic rings with endothelium pre-incubated with various $K^{+}$channel blockers}

We tested the vasorelaxant effect of ADE $(25-800 \mu \mathrm{g} /$ $\mathrm{ml}$ ) on aortic rings with endothelium, that were preincubated with a $\mathrm{K}^{+}$channel blocker such as TEA (5 $\mathrm{mM})$, glibenclamide $(10 \mu \mathrm{M})$, or 4 -AP $(1 \mathrm{mM})$ for $20 \mathrm{~min}$ before PE $(1 \mu \mathrm{M})$ pre-contraction. The vasorelaxant effect of ADE was expressed as percentages of the relaxation in response to $\mathrm{K}^{+}$channel blockers pretreatment on the aortic rings.
Vasorelaxant effects of ADE on extracellular $\mathrm{Ca}^{2+}$-induced contraction contraction (via receptor-operative $\mathrm{Ca}^{2+}$ channels or voltage-dependent $\mathrm{Ca}^{2+}$ channels)

We tested the vasorelaxant effect of ADE (100-400 $\mu \mathrm{g} /$ $\mathrm{ml}$ ) on receptor-operative $\mathrm{Ca}^{2+}$ channels (ROCCs) and voltage-dependent $\mathrm{Ca}^{2+}$ channels (VDCCs) by PE or $\mathrm{KCl}$ pre-treatment. We tested the contraction response induced by $\mathrm{CaCl}_{2}(0.3-10 \mathrm{mM})$ in the aortic rings without endothelium, that were pre-treated by $\mathrm{PE}(1 \mu \mathrm{M})$ or $\mathrm{KCl}$ $(60 \mathrm{mM})$ in $\mathrm{Ca}^{2+}$-free $\mathrm{KH}$ buffer with and without ADE pre-incubation for $10 \mathrm{~min}$. The contraction responses induced by $\mathrm{CaCl}_{2}$ were expressed as percentages in the presence and absence of ADE pre-treatment.

\section{Qualitative and quantitative HPLC analysis of standard materials in ADE}

One gram of ADE was dissolved in $10 \mathrm{ml}$ of methanol (HPLC reagent, J.T. Baker Co. Ltd., U.S.A.) and filtered through a $0.45 \mu \mathrm{m}$ syringe filter $(13 \mathrm{~mm}$ diameter and PVDF membrane, Advantec., Tokyo, Japan). The standard materials used for the qualitative analysis of $\mathrm{ADE}$ were nodakenin and decursin. The standards $(1 \mathrm{mg})$ were serially diluted $(25,50,100$, and $200 \mu \mathrm{g} / \mathrm{ml})$, and an HPLC chromatogram was obtained. Waters e2695 Alliance HPLC system connected with PDA Detector 2998 and Empower2 Software was used for the analysis. The chromatographic separation was achieved using a Sunfire $C_{18}$ reversed-phase column (4.6 mm I.D. $\times 150 \mathrm{~mm}$, $5 \mu \mathrm{m})$ (Waters, Milford, USA), with column oven temperature maintained at $20{ }^{\circ} \mathrm{C}$. The mobile phase consisted of water (Solvent A) and 100\% acetonitrile (Solvent B). The mobile phase flow rate was $1.0 \mathrm{~mL} / \mathrm{min}$ with gradient elution. The percentage composition of Solvent B was maintained at $20 \%$ for 3 min, gradually increased to $30 \%$ for $5 \mathrm{~min}$, maintained at $30 \%$ for $10 \mathrm{~min}$, further increased to $50 \%$ for $1 \mathrm{~min}$ and maintained at $50 \%$ for $21 \mathrm{~min}$. The injection volume was $10 \mu \mathrm{L}$, and UV absorbance was monitored at $330 \mathrm{~nm}$. All solvents were degassed with a micro membrane filter (PTFE, Advantec., Tokyo, Japan). The quantity of the ADE standards was calculated as follows: the amount (mg) of standard material = the quantitative amount (mg) of standard materials $\times \mathrm{A}_{\mathrm{T}} / \mathrm{A}_{\mathrm{S}} / \mathrm{n}\left(n=3 ; \mathrm{A}_{\mathrm{T}}=\right.$ the peak area of the test sample containing the standard; $A_{S}=$ the peak area of the standard).

\section{Statistical analysis}

All data were expressed as mean \pm standard error of mean (SEM). Statistical comparisons were performed using Student's $t$-test. All statistical analysis was performed using SPSS v.21.0 statistical analysis software (SPSS Inc., Chicago, IL, USA). $P$ values less than 0.05 were considered statistically significant while $p$-values less than 0.01 were considered extremely significant. 


\section{Results and discussion}

Sequencing of PCR-amplified DNA from $A$. decursiva

The dried root of $A$. decursiva was amplified by PCR reaction and DNA sequence was analyzed. BLAST search showed that the ITS region of this plant root was 99\% identical to the strain of $A$. decursiva (GenBank ID: AY548220). Especially, ITS2 region also corresponded 99\% identity with of $A$. decursiva (GenBank ID: KP334175). The DNA sequence of $A$. decursiva ITS2 region was as follow:

NNNNNGTNNCNCNNAGTCTTTGACGCAAGT

TGCGCCCGAAGCCACTAGGC.

TGAGGGCACGCCTGCCTGGGTGTCACGCATCG

TATTGCCTGCAGACCACT.

CACACCTGAGAAGTTGTGACGGTTTGGGGCG

CAAATTGGCCTCCCGTACC.

TTGTCGTGCGGTTGGCGGAAAAACGAGTCTC CGGCGACGGATGTCGCGAC.

ATCGGTGGTTGTGAAAGACCCTCTTGTCTTG

TCGCGCGAGTCCTCGTCAT.

CTTAGCGAGCTCCAGGACCCATAGGCAGCACA

CACTCTGTGCGCTTCGAC.

TGTGACCCCAGGTCAGGCGGGACTACCCGCT

GAGTTTAAGCATATCAATA.

AGCGGAGGAAAAGAAACTTACAAGGATTCCCC

TAGTAACGGCGAGCGAAC.

CGGGAACAGCCCAGCTTGAAAATTGGTCGGCT

CTGCCTTCCGAATTGTAG.

TCTAGCAAGCGTCAGTGGCAGTACGTGGGGTA

GATGTGTTCTGACGCGCC.

GGGCGGGGTGGCCTCTGCGCGAGACTAGAAAA

ATGAAAGTAGTTAAAGGA.

CCCCCGGCCGCCCACATTCTACCCCCCTTC

GATGTAACAAAAGGTNTGCT.

TNATACAATTAAAATANACGTAACTANN.

Vasorelaxant effects of ADE on PE (or $\mathrm{KCl}$ )-induced contraction

ADE concentration-dependently caused relaxation in PE

$(1 \mu \mathrm{M})$ or $\mathrm{KCl}(60 \mathrm{mM})$ precontracted aortic rings with intact endothelium. The maximal relaxant effect was $90.1 \pm 2.0 \%$ and $94.3 \pm 1.8 \%$ at the concentration of $800 \mu \mathrm{g} / \mathrm{ml}$, respectively (Fig. 1).

\section{Relationship between vascular endothelium and ADE on $\mathrm{PE}$ (or $\mathrm{KCl}$ )-induced contraction}

ADE showed concentration-dependent relaxation in both endothelium-intact and endothelium-denuded aortic rings precontracted by $\mathrm{PE}(1 \mu \mathrm{M})$ or $\mathrm{KCl}(60 \mathrm{mM})$. The maximal relaxant effect on PE-induced contraction was $90.1 \pm 2.0 \%$ and $95.5 \pm 3.8 \%$ for endothelium-intact and endotheliumdenuded aortic rings, respectively (Fig. 2). The maximal relaxant effect on $\mathrm{KCl}$-induced contraction was $94.3 \pm 1.8 \%$ and $96.9 \pm 2.2 \%$ for endothelium-intact and endotheliumdenuded aortic rings, respectively (Fig. 2).

In this study, the maximal vasorelaxant effect of ADE was observed at a dose of $800 \mu \mathrm{g} / \mathrm{mL}$. Few studies have demonstrated the various biological effects of $A$. decursiva; however, its vasorelaxant effect remains unclear. Natural products from medicinal plants have been used to treat human diseases for thousands of years. Currently, approximately $80 \%$ of the population in developing countries uses herbal medicines. The demand for medicinal plants for treating hypertension is increasing [12]. A. decursiva may play an important role in hypertension management in the future.

Normal endothelial cells play an important role in the human vascular system. They control blood pressure and vascular tone by secreting potent vasodilators or vasoconstrictors [27]. In the present study, ADE induced concentration-dependent relaxation, which was not related to endothelial function, in both the whole-endothelium and endothelium-removed aortic rings pre-contracted with $\mathrm{KCl}$ or $\mathrm{PE}$, indicating that the vasorelaxant effect of $\mathrm{ADE}$ was endothelium-independent.

Vasorelaxant effect of ADE on aortic rings preincubated with TEA ( $\mathrm{K}_{\mathrm{Ca}}$ channels blocker), glibenclamide ( $\mathrm{K}_{\mathrm{ATP}}$ channels blocker), or 4-AP ( $\mathrm{K}_{\mathrm{V}}$ channels blocker)

Incubation with TEA $(5 \mathrm{mM})$ or 4 -AP $(1 \mathrm{mM})$ did not affect $\mathrm{ADE}$-induced relaxation on endothelium-intact
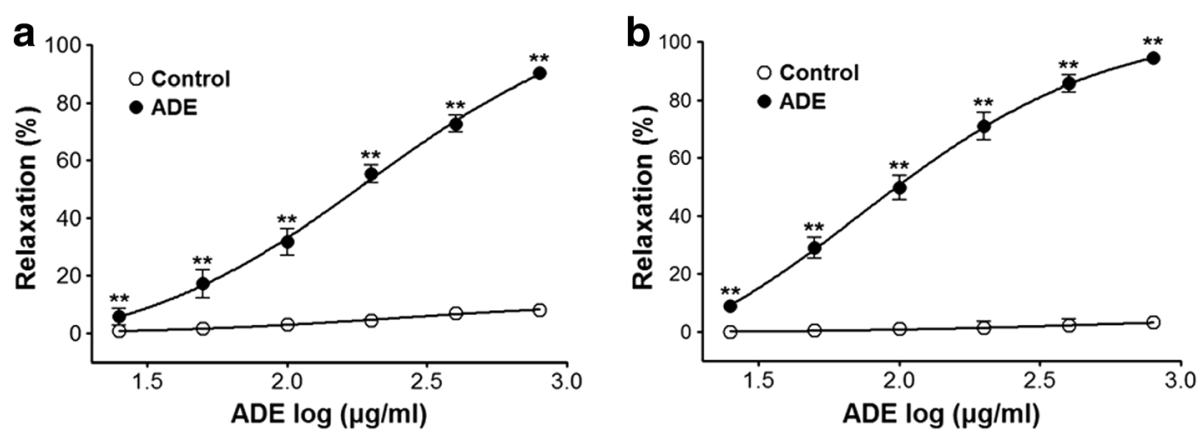

Fig. 1 Relaxation effect of ADE $(25-800 \mu \mathrm{g} / \mathrm{mL})$ on PE (1 $\mu \mathrm{M})(\mathbf{a})$ or $\mathrm{KCl}(60 \mathrm{mM})(\mathbf{b})$-precontracted aortic rings. Values are expressed as the mean $\pm \operatorname{SEM}\left(n=5-8\right.$, number of aortic rings). ${ }^{* *} P<0.01$ vs. control 

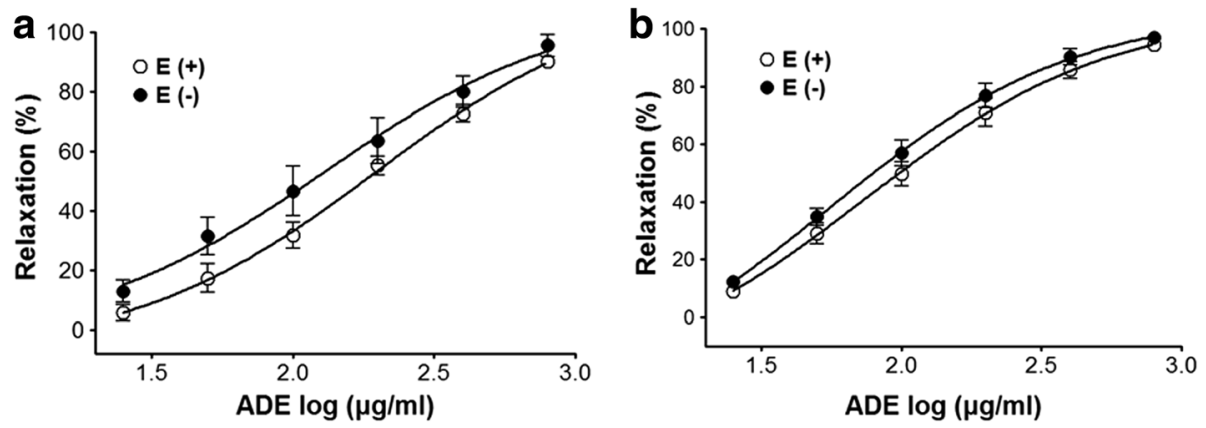

Fig. 2 Concentration-dependent relaxant effect of ADE on PE $(1 \mu \mathrm{M})(\mathbf{a})$ or $\mathrm{KCl}(60 \mathrm{mM})(\mathbf{b})$ precontracted endothelium-intact $[(\mathrm{E}+)]$ and endothelium-denuded $[(E-)]$ aortic rings. Values are expressed as mean $\pm \operatorname{SEM}(n=5-8$, number of aortic rings)

aortic rings contracted by PE $(1 \mu \mathrm{M})$ treatment (Fig. 3). The vasorelaxant effects of ADE $(25-200 \mu \mathrm{g} / \mathrm{ml})$ on PE $(1 \mu \mathrm{M})$ precontracted endothelium-intact aortic rings were altered by glibenclamide $(10 \mu \mathrm{M})$. In the presence of glibenclamide, the ADE-induced relaxant effect was of $45.5 \pm 4.2 \%$ vs. the not pre-treated control group $55.2 \pm 3.1 \%$ at the concentration of $200 \mu \mathrm{g} / \mathrm{ml}$ (Fig. 3). In these experiments, the vasorelaxant effect of $\mathrm{ADE}$ was not affected by endothelial function. Therefore, we concluded that there might be a correlation between the vasorelaxant effect of ADE and vascular smooth muscle.

Diverse ion channels in the vascular smooth muscle cells, endothelial cells, and pericytes play important roles in microcirculation. Microvascular smooth muscle cells have at least four different types of $\mathrm{K}^{+}$channels such as inward-rectifier $\mathrm{K}^{+}\left(\mathrm{K}_{\mathrm{IR}}\right)$ channels, ATP-sensitive $\mathrm{K}^{+}$ $\left(\mathrm{K}_{\text {ATP }}\right)$ channels, voltage-gated $\mathrm{K}^{+}\left(\mathrm{K}_{\mathrm{V}}\right)$ channels, and $\mathrm{Ca}^{2+}$-activated $\mathrm{K}^{+}\left(\mathrm{K}_{\mathrm{Ca}}\right)$ channels [28]. To determine which types of $\mathrm{K}^{+}$channels are involved in the vasorelaxant effect of $\mathrm{ADE}$, various $\mathrm{K}^{+}$channel blockers such as glibenclamide ( $\mathrm{K}_{\mathrm{ATP}}$ channel blocker), 4-AP ( $\mathrm{K}_{\mathrm{V}}$ channel blocker), and TEA ( $\mathrm{K}_{\mathrm{Ca}}$ channel blocker) were used [29]. The vasorelaxant effect of ADE was partially weakened by pre-treatment with glibenclamide. Thus, the vasorelaxant effect of $\mathrm{ADE}$ on rat aortic rings is correlated with $\mathrm{K}^{+}$channels, particularly $\mathrm{K}_{\mathrm{ATP}}$ channels.
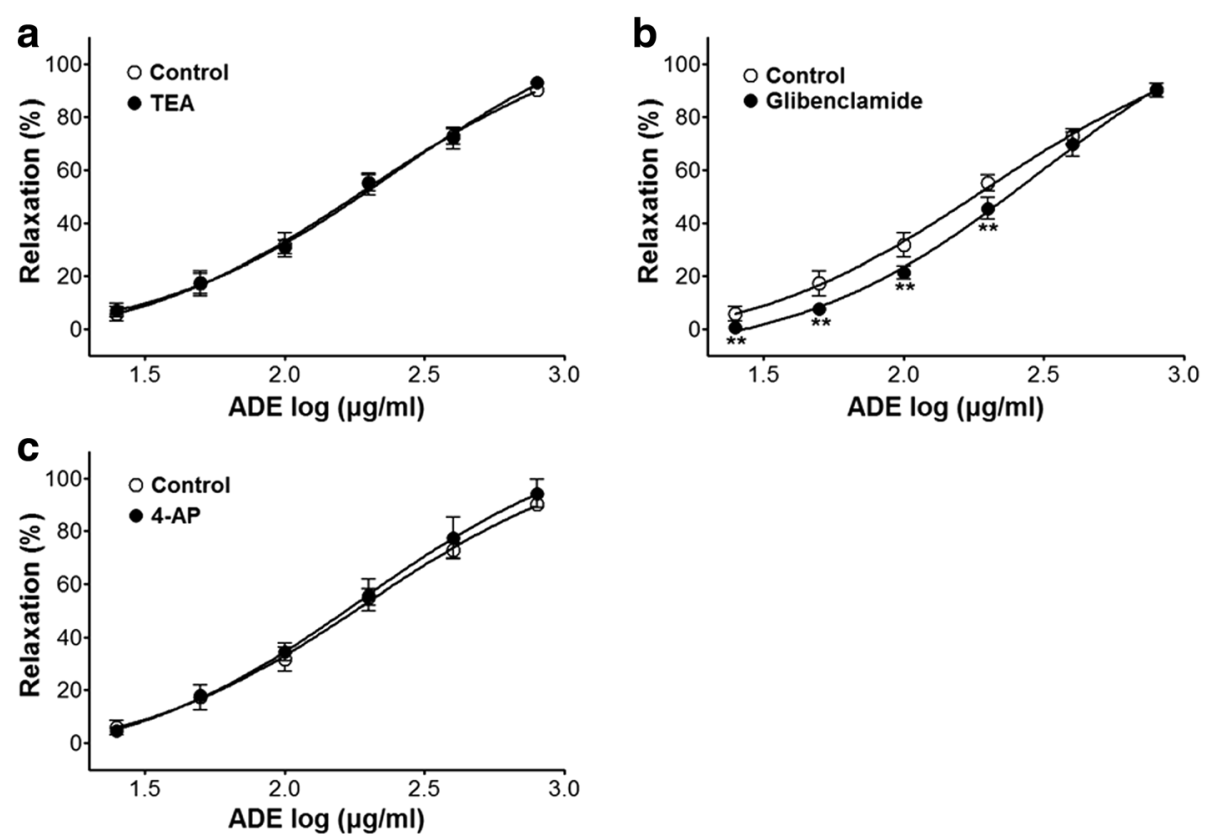

Fig. 3 Concentration-response curves to ADE on endothelium-intact aortic rings precontracted by PE $(1 \mu \mathrm{M})$ in the presence or absence (not pre-treated control) of TEA $(5 \mathrm{mM})(\mathbf{a})$, glibenclamide $(10 \mu \mathrm{M})(\mathbf{b})$, or 4-AP $(1 \mathrm{mM})(\mathbf{c})$. Values are expressed as mean \pm SEM $(n=5-8$, number of aortic rings). ${ }^{* *} P<0.01$ vs. control 

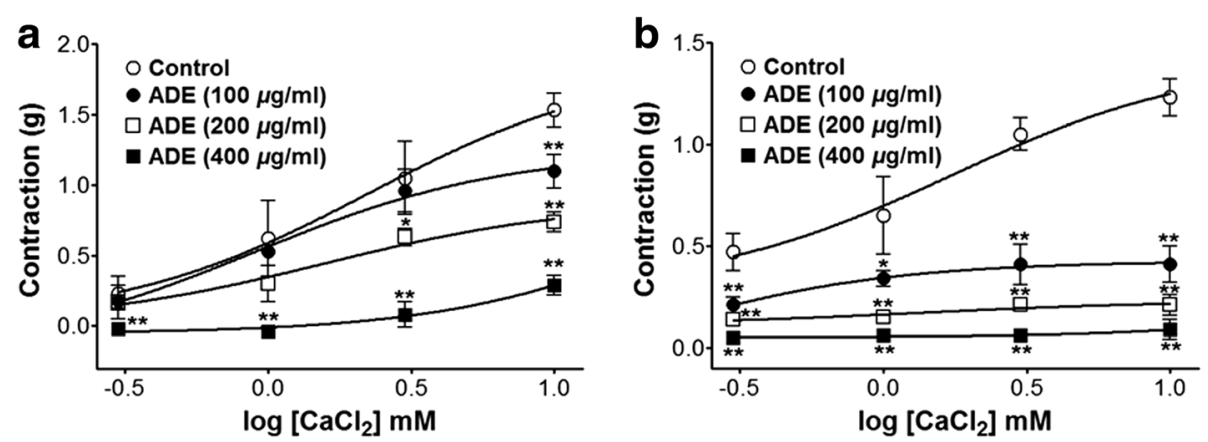

Fig. 4 Inhibitory effect of ADE (100-400 $\mu \mathrm{g} / \mathrm{ml})$ on the contraction induced by extracellular $\mathrm{Ca}^{2+}$ in endothelium-denuded rat thoracic aorta rings pretreated by PE $(1 \mu \mathrm{M})(\mathbf{a})$ or $\mathrm{KCl}(60 \mathrm{mM})(\mathbf{b})$ in the presence or absence (not pre-treated control) of ADE. Values are expressed as mean $\pm \mathrm{SEM}$ ( $\mathrm{n}=5$, number of aortic rings). ${ }^{*} P<0.05,{ }^{* *} P<0.01$ vs. control

Effect of ADE on extracellular $\mathrm{Ca}^{2+}$-induced contraction (via ROCCs or VDCCs)

In $\mathrm{Ca}^{2+}$-free $\mathrm{KH}$ buffer, the addition of $\mathrm{CaCl}_{2}(0.3-10 \mathrm{mM})$ induced gradual increased tension on endothelium-denuded aortic rings by $\mathrm{PE}(1 \mu \mathrm{M})$ or $\mathrm{KCl}(60 \mathrm{mM})$ treatment. Preincubation with ADE $(100-400 \mu \mathrm{g} / \mathrm{ml})$ significantly inhibited the contractions induced by extracellular $\mathrm{CaCl}_{2}(10 \mathrm{mM})$ and the contraction at $\mathrm{ADE}(400 \mu \mathrm{g} / \mathrm{ml})$ was decreased to $0.29 \pm 0.07 \mathrm{~g}$ and $0.09 \pm 0.05 \mathrm{~g}$ compare to the not pretreated control group $1.53 \pm 0.12 \mathrm{~g}$ and $1.23 \pm 0.09 \mathrm{~g}$, in cells pre-contracted by $\mathrm{PE}$ and $\mathrm{KCl}$, respectively (Fig. 4).

Vascular smooth muscle contraction is triggered by an increase in intracellular calcium, which is released from intracellular $\mathrm{Ca}^{2+}$ stores [30]. Extracellular $\mathrm{Ca}^{2+}$ influx through ROCCs or VDCCs increases intracellular calcium levels. Vasodilatation is caused by inhibition of extracellular $\mathrm{Ca}^{2+}$ entry through ROCCs or VDCCs in the plasma membrane [31]. ROCCs and VDCCs can be activated by $\mathrm{PE}$ and $\mathrm{KCl}$, respectively [32]. ADE inhibited vasoconstriction induced by supplementation of $\mathrm{Ca}^{2+}$ in the aortic rings that had been pre-constricted with $\mathrm{PE}$ or $\mathrm{KCl}$ in $\mathrm{Ca}^{2}$ ${ }^{+}$-free $\mathrm{KH}$ buffer. This finding suggests that ADE considerably inhibited the permeation of extracellular $\mathrm{Ca}^{2+}$ via ROCCs or VDCCs activated by $\mathrm{PE}$ or $\mathrm{KCl}$, respectively.

Many compounds such as decursin, imperatorin, isoimperatorin, umbelliferone, bergapten, and nodakenin have been isolated from $A$. decursiva. Previous studies have shown that decursin and nodakenin have antihypertensive effects. Decursin and nodakenin lowered the blood pressure in the carotid artery of rabbits [33], and a decursin and decursinol angelate mixture showed a significant vasorelaxant activity in male Sprague-Dawley rats [34]. Similarly, various compounds including decursin or nodakenin may be responsible for the vasorelaxant effects of $A$.
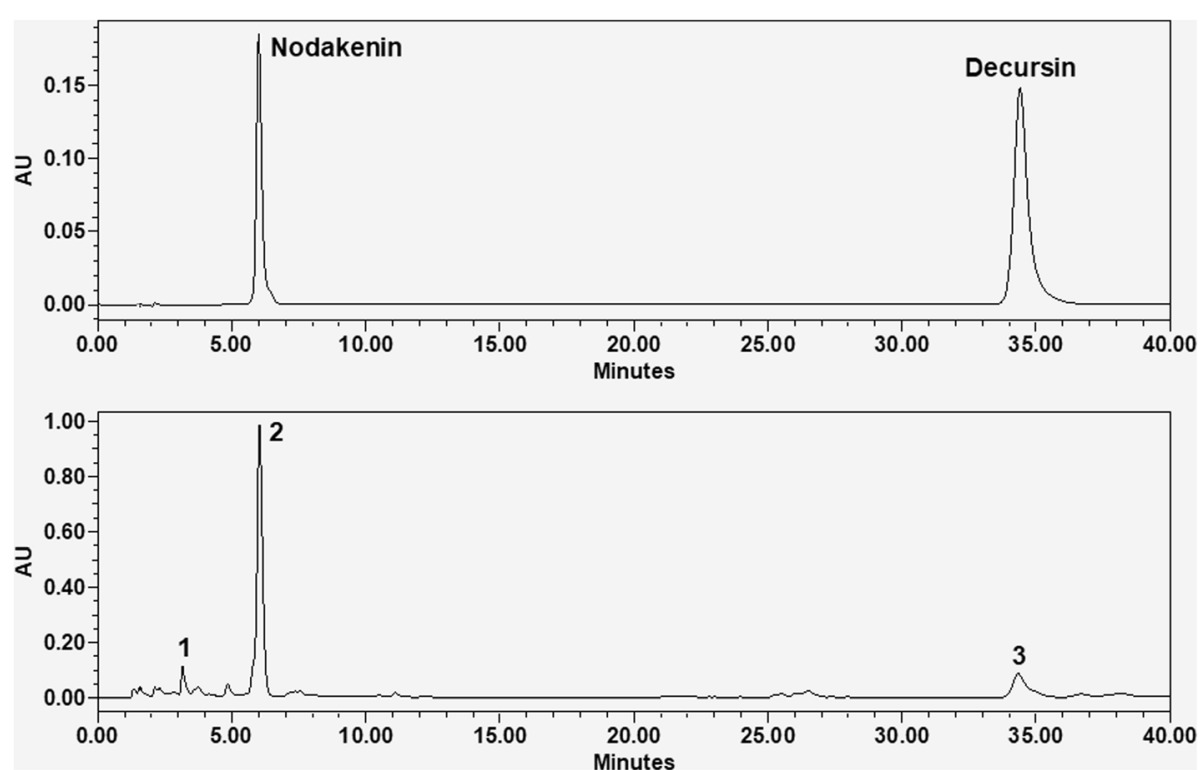

Fig. 5 Qualitative and quantitative HPLC analysis of standard materials in ADE. The retention time of the peak 1, peak 2 (nodakenin), peak 3 (decursin) was $3.2,6.1$, and 34.4 min, respectively 
decursiva. Hence, $A$. decursiva is thought to be effective as a vasodilator for treating hypertension. Additional studies of these compounds may help to determine the exact mechanism underlying the vasorelaxant effect of ADE in rat aortic rings.

\section{Qualitative and quantitative HPLC analysis of standard materials in $\mathrm{ADE}$}

The retention times of the peaks in HPLC were $3.2 \mathrm{~min}$ (peak 1), $6.1 \mathrm{~min}$ (peak 2, nodakenin), and 34.4 min (peak 3, decursin) (Fig. 5). The standard curve was calibrated by using the linear regression derived from the peak area. The regression equation (correlation coefficient, $R^{2}$ ) of nodakenin and decursin were $y=26,923.15 x-21,599.52$ (0.999) and $y=55,531.57 \times-39,679.81$ (0.999), exhibited good linearity. The content of nodakenin and decursin in $1 \mathrm{~g}$ of ADE were $0.562 \pm 0.003 \mathrm{mg}$ (nodakenin) and $0.063 \pm 0.001 \mathrm{mg}$ (decursin).

\section{Conclusions}

In conclusion, (1) the vasorelaxant effects of ADE were endothelium independent, (2) $\mathrm{K}^{+}$channels such as $\mathrm{K}_{\mathrm{ATP}}$ channels were partly related to $\mathrm{ADE}$-induced vasorelaxation, and (3) ADE relaxed the aortic rings by blocking the entry of extracellular $\mathrm{Ca}^{2+}$ via ROCCs and VDCCs.

\begin{abstract}
Abbreviations
4-AP: 4-aminopyridine; Ach: Acetylcholine; ADE: The 70\% EtOH extract of A. decursiva root; $\mathrm{CaCl}_{2}$ : Calcium chloride; $\mathrm{CVD}$ : The cardiovascular disease; DMSO: Dimethyl sulfoxide; EGTA: Ethylene glycol-bis (2-aminoethylether)$N, N, N^{\prime}, N^{\prime}$-tetra acetic acid; $K_{\text {ATP: }}$ : ATP-sensitive $\mathrm{K}^{+}$channels; $\mathrm{K}_{\mathrm{Ca}}: \mathrm{Ca}^{2+}$-activated $\mathrm{K}^{+}$channels; KCl: Potassium chloride; KH: Krebs-Henseleit; $\mathrm{K}_{\mathbb{R}}$ : Inward-rectifier $\mathrm{K}^{+}$channels; $\mathrm{K}_{\mathrm{v}}$ : Voltage-gated $\mathrm{K}^{+}$channels; NCDs: Noncommunicable diseases; PE: Phenylephrine; ROCCs: receptor-operative $\mathrm{Ca}^{2+}$ channels; TEA: Tetraethylammonium; VDCCs: voltage-dependent $\mathrm{Ca}^{2+}$ channels
\end{abstract}

\section{Acknowledgments}

\section{Funding}

No funding was received.

\section{Availability of data and materials}

The contents of this manuscript were argued and useful on requirement from the corresponding author.

\section{Authors' contributions \\ BK and SL performed the animal experiments. BK and YK participated in the writing of the manuscript. $\mathrm{IH}$ and $\mathrm{KL}$ conceived the study and participated in its design and coordination. HC helped draft the manuscript. All authors read and approved the final manuscript. \\ Ethics approval \\ All procedures followed according to the animal welfare guidelines and were approved [KHUASP(SE)-15-066] by the Kyung Hee University Institutional Animal Care and Use Committee.}

\section{Consent for publication}

The authors agreed to publish the results of this study.

\section{Competing interests}

The authors declare that they have no competing interests.

\section{Publisher's Note}

Springer Nature remains neutral with regard to jurisdictional claims in published maps and institutional affiliations.

\section{Author details}

${ }^{1}$ Department of Herbology, College of Korean Medicine, Kyung Hee University, 26 Kyungheedae-ro, Dongdaemun-gu, Seoul 02447, Republic of Korea. ${ }^{2}$ Department of Herbology, Graduate School, Kyung Hee University, Seoul, Republic of Korea.

Received: 19 February 2017 Accepted: 1 September 2017

Published online: 02 October 2017

\section{References}

1. Kjeldsen S, Feldman RD, Lisheng L, Mourad JJ, Chiang CE, Zhang W, Wu Z, Li W, Williams B. Updated national and international hypertension guidelines: a review of current recommendations. Drugs. 2014;74(17):2033-51.

2. World Health Organization. Global status report on noncommunicable diseases 2014. Geneva: World Health Organization; 2014.

3. Choi S. Prevalence and perception levels for essential hypertension: the third Korea national health and nutrition examination survey, Unpublished master's thesis. Seoul: Korea University; 2009.

4. Bethesda. The seventh report of the joint National Committee on prevention, detection, evaluation, and treatment of high blood pressure; 2004. p. 04-5230.

5. Lionakis N, Mendrinos D, Sanidas E, Favatas G, Georgopoulou M. Hypertension in the elderly. World J Cardiol. 2012;4(5):135-47.

6. Lee NR, Go TH, Lee SM, Jeong SY, Park GT, Hong CO, Son HJ. In vitro evaluation of new functional properties of poly-gamma-glutamic acid produced by Bacillus Subtilis D7. Saudi J Biol Sci. 2014;21(2):153-8.

7. Chandra KS, Ramesh G. The fourth-generation calcium channel blocker: cilnidipine. Indian Heart J. 2013;65(6):691-5.

8. Kim JH, Kim KK, Jeong HC, Lee SY, Kwon YH, Lee SR, Lee SY, Lee SH, Cha DR, Cho JY, Shim JJ, Cho WY, Kang KH, Kim HK, Yoo SH, In KH. Correlation between angiotensin-converting enzyme (ACE) inhibitor induced dry cough and ACE gene insertion/deletion (I/D) polymorphism. Tuberc Respir Dis. 1999:46(2):241-50.

9. Fichman MP, Vorherr H, Kleeman CR, Telfer N. Diuretic-induced hyponatremia. Ann Intern Med. 1971;75(6):853-63.

10. Grimm RH Jr, Grandits GA, Prineas RJ, McDonald RH, Lewis CE, Flack $J M$, Yunis C, Svendsen K, Liebson PR, Elmer PJ. Long-term effects on sexual function of five antihypertensive drugs and nutritional hygienic treatment in hypertensive men and women. Treatment of mild hypertension study (TOMHS). Hypertension. 1997;29(1 Pt 1):8-14.

11. Ramsay LE, Yeo WW, Jackson PR. Influence of diuretics, calcium antagonists, and alpha-blockers on insulin sensitivity and glucose tolerance in hypertensive patients. J Cardiovasc Pharmacol. 1992; 20(Suppl 11):S49-53. discussion S53-4

12. Tabassum N, Ahmad F. Role of natural herbs in the treatment of hypertension. Pharmacogn Rev. 2011;5(9):30-40.

13. Ibarra-Alvarado C, Rojas A, Mendoza S, Bah M, Gutierrez DM, HernandezSandoval L, Martinez M. Vasoactive and antioxidant activities of plants used in Mexican traditional medicine for the treatment of cardiovascular diseases. Pharm Biol. 2010;48(7):732-9.

14. Common Editing Commission. Bonchohak. Younglimsa. 2011;496-7.

15. Islam MN, Choi RJ, Jin SE, Kim YS, Ahn BR, Zhao D, Jung HA, Choi JS. Mechanism of anti-inflammatory activity of umbelliferone 6-carboxylic acid isolated from Angelica decursiva. J Ethnopharmacol. 2012;144(1): 175-81.

16. Shin W, Kim C, Kim H, Lee M, Kim H, Kim D. Growth inhibition of human head and neck squamous cell carcinomas by Angelica decursiva extracts. International journal of oral biology: official journal of the Korean Academy of Oral Biology and the UCLA Dental Research Institute. 2010;35(4):153-8.

17. Lee M, Kim M, Kook J, Kim D, Kim H, Kim H, Kim C. Ethanol extracts of Angelica decursiva induces apoptosis in human oral cancer cells. International journal of oral biology: official journal of the Korean Academy of Oral Biology and the UCLA Dental Research Institute. 2010;35(4):215-20.

18. Lim H, Shin S. Study on the essential oils from the roots of Angelica decursiva and Peucedanum praeruptorum. Kor J Pharmacogn. 2012;43(4):291-6. 
19. Hata K, Sano K. Studies on coumarins from the root of Angelica decursiva FR. et SAV. I. The structure of decursin and decursidin. Yakugaku Zasshi. 1969; 89(4):549-57.

20. Avramenko LG, Nikonov GK, Pimenov MG. Andelin-a new dihydropyranocoumarin from the roots of Angelica decursiva. Khimiya Prirodnykh Soedinenii. 1970;6(2):186-9.

21. Chen YC, Chen PY, Wu CC, Tsai IL, Chen IS. Chemical constituents and anti-platelet aggregation activity from the root of Peucedanum formosanum. J Food Drug Anal. 2008;16:15-25.

22. Downie SR, Katz-Downie DS, Watson MF. A phylogeny of the flowering plant family Apiaceae based on chloroplast DNA rpl16 and rpoC1 intron sequences: towards a suprageneric classification of subfamily Apioideae. Am J Bot. 2000; 87(2):273-92.

23. Lee K, Shin MS, Ham I, Choi HY. Investigation of the mechanisms of Angelica dahurica root extract-induced vasorelaxation in isolated rat aortic rings. BMC Complement Altern Med. 2015;15:395.

24. Lee K, Park G, Ham I, Yang G, Lee M, Bu Y, Kim H, Choi HY. Vasorelaxant effect of Osterici radix ethanol extract on rat aortic rings. Evid Based Complement Alternat Med. 2013;2013:350964.

25. Kim B, Lee K, Chinannai KS, Ham I, Bu Y, Kim H, Choi HY. Endotheliumindependent vasorelaxant effect of Ligusticum jeholense root and rhizoma on rat thoracic aorta. Molecules. 2015;20(6):10721-33.

26. Kim EY, Rhyu MR. Synergistic vasorelaxant and antihypertensive effects of Ligusticum wallichii and Angelica gigas. J Ethnopharmacol. 2010; 130(3):545-51.

27. Pearson JD. Normal endothelial cell function. Lupus. 2000:9(3):183-8.

28. Jackson WF. Potassium channels in the peripheral microcirculation. Microcirculation. 2005;12(1):113-27.

29. Novakovic A, Bukarica LG, Kanjuh V, Heinle H. Potassium channels-mediated vasorelaxation of rat aorta induced by resveratrol. Basic Clin Pharmacol Toxicol. 2006;99(5):360-4.

30. Broekaert A, Godfraind T. A comparison of the inhibitory effect of cinnarizine and papaverine on the noradrenaline- and calcium-evoked contraction of isolated rabbit aorta and mesenteric arteries. Eur J Pharmacol. 1979;53(3):281-8.

31. Cao YX, Zhang W, He JY, He LC, Xu CB. Ligustilide induces vasodilatation via inhibiting voltage dependent calcium channel and receptor-mediated $\mathrm{Ca}^{2+}$ influx and release. Vasc Pharmacol. 2006;45(3):171-6.

32. Hoe SZ, Lee CN, Mok SL, Kamaruddin MY, Lam SK. Gynura procumbens Merr. decreases blood pressure in rats by vasodilatation via inhibition of calcium channels. Clinics (Sao Paulo). 2011;66(1):143-50.

33. Chi HJ, Kim HS. Studies on the components of Umbelliferae plants in Korea: pharmacological study of decursin, decursinol and nodakenin. Kor J Pharmacog. 1970;1(1):25-32.

34. Kim HH, Choi S, Shim B, Yu YB, Ahn DK, Choi HY, Park SK, Kim H, Shin JS, Kim H, Ahn K. Blood vessel relaxational agent containing decursin or decursinol angelate. Korea Patent. 2006; 10-0633096-0000.

\section{Submit your next manuscript to BioMed Central and we will help you at every step:}

- We accept pre-submission inquiries

- Our selector tool helps you to find the most relevant journal

- We provide round the clock customer support

- Convenient online submission

- Thorough peer review

- Inclusion in PubMed and all major indexing services

- Maximum visibility for your research

Submit your manuscript at www.biomedcentral.com/submit

CBiomed Central 